\title{
Imágenes del narcotráfico. 20 adaptaciones audiovisuales de la figura de Pablo Escobar en el siglo XXI. Usos de material de archivo en producciones de narco-ficción y documental
}

\author{
Images of drug trafficking. 20 audiovisual adaptations of the \\ figure of Pablo Escobar in the 21st century. Uses of archival \\ material in narco-fiction and documentary productions
}

\author{
Alzate Giraldo, A. A., Cardona Cano, C. A. y Díaz Arenas, P. F. ${ }^{1}$ \\ Recibido: 27-03-2021 - Aceptado: 05-08-2021 \\ https://doi.org/10.26441/RC20.2-2021-A1
}

RESUMEN: El presente artículo estudia todas las adaptaciones audiovisuales sobre la figura del narcotraficante Pablo Escobar Gaviria durante el siglo XXI, (2000-2018). Producciones que se enmarcan en el contexto de las llamadas narcoseries, basadas en historias reales. Dichas series se apoyan en el material de archivo para la construcción de relatos a partir de la realidad. El estudio toma como eje principal el uso del material de archivo en dichas producciones. Son analizadas 20 adaptaciones compuestas por series, documentales y unitarios de ficción. Las 20 producciones estudiadas son caracterizadas de manera sistemática, presentando las diferencias en función de los países de la producción e identificando de manera cualitativa y cuantitativa los diversos usos del material de archivo, fotografías, videos, audios provenientes de noticias, archivos privados y álbumes familiares que soporta el componente de realidad para contar historias basadas en hechos reales.

Palabras clave: narcoseries; archivo audiovisual; narcotráfico; ficción, documental; Pablo Escobar.

\begin{abstract}
This article studies all the audiovisual adaptations on the figure of the drug trafficker Pablo Escobar Gaviria during the XXI century, (2000-2018). Productions that are framed in the context of the so-called narco series, based on real stories. These series are supported by the archive material for the construction of stories based on reality. The study takes as its main axis the use of archive material in these productions. 20 adaptations made up of series, documentaries, and fiction units are analyzed. The 20 productions studied are characterized in a systematic way, presenting the differences according to the countries of production and identifying in a qualitative and quantitative way the various uses of archive material, photographs, videos, audios from news, private archives, and family albums that supports the reality component to tell stories based on real events.
\end{abstract}

Keywords: narcoseries; audiovisual archive; drug trafficking; fiction; documentary; Pablo Escobar.

\footnotetext{
${ }^{1}$ Alberto Alejandro Alzate Giraldo es Doctor en Estudios avanzados de arte contemporáneo, Máster en Investigación y producción artística y máster en Antropología por la Universidad de Barcelona, director del Centro de Investigación en Comunicación y profesor de las asignaturas Realización documental y Seminario de investigación en la Facultad de Comunicación de la Universidad de Medellín (Colombia). aalzate@udem.edu.co, http://orcid.org/0000-0002-1634-9982

César Alonso Cardona Cano es Magister en Comunicación Educativa por la Universidad Tecnológica de Pereira y docente a tiempo completo de la asignatura Sonido en la Facultad de Comunicación de la Universidad de Medellín (Colombia). ccardona@udem.edu.co, http://orcid.org/0000-0003-4163-2752

Pedro Felipe Díaz Arenas es Doctor en Ciencias de la Educación por la Universidad Tecnológica de Pereira y docente de la asignatura Trabajo de grado en la Facultad de Comunicación de la Universidad del Quindío (Colombia). pfdiaz@uniquindio.edu.co, http://orcid.org/0000-0002-6862-7948
} 


\section{Introducción ${ }^{2}$}

Las series y novelas han sido durante años una forma de narrar la historia. Existe una expresión que se ha posicionado para mencionar aquellas que tocan el tema de las drogas, la mafia y los procesos del narcotráfico en distintos territorios: las narcoseries. Estas han tomado como referencia para sus historias hechos asociados al narcotráfico ocurridos en países como Colombia y México generando imaginarios sobre la realidad de lo que se ve en la pantalla. Estos productos interpretan el fenómeno del narcotráfico a través de largometrajes de ficción y documental, así como seriales, en ambos géneros. El proceso narrativo en los diferentes géneros se configura de formas diversas, la narrativa alrededor del narcotráfico aborda los hechos históricos de la violencia ocurrida en estos lugares. Sin embargo, comparten elementos que los vinculan a la realidad. Uno de estos elementos es el uso del material de archivo como estrategia narrativa, que genera un vínculo estrecho con los hechos históricos asociados al narcotráfico, teniendo en cuenta la relación que estas producciones tienen con la realidad y como han sido narradas las realidades sociales en latinoamérica (Rivas Frías, 2020).

Las narcoseries han generado imaginarios sobre los protagonistas, exaltando la figura del narcotraficante. Morales y Carrillo. (2017) afirman: "han aparecido prácticas sociales y culturales negativas que se convierten en apología de los hechos delictivos conectados con las drogas; se elogia la riqueza obtenida por los actores del narcotráfico y se exaltan sus figuras" (p.196). En el caso de este estudio, son analizadas las adaptaciones sobre la figura de Pablo Escobar, clasificando los contenidos y los países de las producciones en donde se genera un estudio sobre el material de archivo, el cual es usado como elemento de validación y vinculación con la realidad en la pantalla. Resultado de los usos y categorías de dicho material, la clasificación propuesta permite contrastar los países de realización y los usos narrativos que estas producciones le dan al archivo audiovisual. Para este artículo fueron analizadas 20 adaptaciones sobre la figura de Pablo Escobar dentro de las cuales se encuentran 8 contenidos de ficción, de ellos 3 seriados de ficción y 5 largometrajes; 12 contenidos documentales producidos entre el año 2000 y 2018. Rodríguez-Blanco y Mastrogiovanni (2018) enfatiza en cómo las imágenes de los medios generan una sensación de veracidad, ya que cuenta con una parte del pasado inserto en ficción que se combina con documentos históricos con imaginarios populares, pero que no tienen que ser verificados.

\section{Producciones audiovisuales que narran el narcotráfico}

Las denominadas "narcoseries" se han encargado de la configuración de imaginarios sobre países como Colombia y México, presentando la delincuencia y la violencia como elementos que hacen parte de la identidad de estos países. La serie Narcos (2015), por ejemplo, desarrolla su primera y segunda temporada en el caso Colombia y la tercera temporada en el caso de México, generan una representación del contexto que Becerra (2018) explica cómo las "representaciones e imaginarios sociales sobre el tráfico de drogas, que llegan a configurar un mundo de vida [...] y seducen a una gran cantidad de personas al convertirse en anhelos que van desde el consumo y apropiación de los contenidos simbólicos" (p.10). Es decir, instrumentalizar los códigos culturales. En Becerra y Hernández y encontramos:

Una variedad de formas: música, literatura, cine, series de televisión, arquitectura, religión, artes plásticas, videojuegos, cómics, lenguaje y vestimenta. Además, mezcla aspectos de la cultura popular (...) que tienden a exaltar la opulencia, transgresión, impunidad y el poder; por lo tanto, no solo constituyen expresiones estéticas, sino también éticas (p.2).

\footnotetext{
2 Este trabajo es resultado del proyecto de investigación "20 adaptaciones sobre la figura de Pablo Escobar en el audiovisual en el siglo XXI. Periodo: 2000-2018". Financiado por la Universidad de Medellín y la Universidad del Quindío. Colombia
} 
Así pues, encontramos que estas series son asociaciones al narcotráfico que han reforzado la estigmatización que se tienen sobre estos países, robusteciendo los discursos de dominación hegemónica que se han planteado desde inicio del conflicto del narcotráfico, regulado a través de leyes realizadas por el parlamento de los EE. UU.

Los contenidos abordados en este caso sobre el narcotráfico son entonces mediados por una condición política que refuerza la imagen proyectada a través del formato, bien sea sobre el antagonista o el protagonista y su papel en el contexto de la historia. Estas narrativas se han ido enmarcando a través de formatos como la narcotelenovela, la narcoserie, el largometraje o la serie documental, cada una con sus particularidades. Realizando apropiaciones del pasado, Rodríguez-Blanco y Mastrogiovanni (2018) retoman la noción de un pasado utilizable en donde son usados supuestamente los hechos históricos abordados desde el periodismo. Tal y como se expuso en el anterior apartado, la relación entre cine e historia ha dado paso a múltiples análisis en el campo académico, pensando en la construcción cinematográfica como constructora de sentido del pasado. Esto se encarga de generar una suerte de pasado construido a partir de fusiones entre ficciones y materiales reales usados en función del producto audiovisual, generando entonces nociones sobre la historia.

Para este tipo de producciones, Rincón (2009), enumera ciertos elementos que pueden describir la forma en que se presenta a Colombia como una nación hija del narcotráfico y cómo los narcos en estas versiones tienen una imagen ficcional y legítima en la pantalla colombiana. De la misma forma se construye una versión de Colombia o de los lugares en dichas producciones, se aborda también el concepto de violencia, desde una representación cruda. Santos (2016) explica cómo estas producciones se han basado en el detalle de situaciones violentas, torturas y sangre; acciones que obedecen a instintos básicos como el amor, el odio y el interés monetario. Adicionalmente, Rodríguez-Blanco y Mastrogiovanni (2018) encuentran en las representaciones del narcotráfico que se muestran en la pantalla, una explicación sobre el hecho de que estos productos sean colocados en el imaginario colectivo al mismo nivel de narraciones históricas.

La proliferación de este tipo de contenidos producidos principalmente en los EE. UU. establece una hegemonía sobre los territorios que es ejercida de diversas formas. Williams (1997) menciona cómo a través de los códigos sociales se reflejan la injusticia, la inequidad, la pobreza y la miseria a través del cine, y que puede ser a través de ese mismo medio que se pueden generar contenidos "contrahegemónicos" o propios de una hegemonía alternativa como un elemento real y persistente. Estos contenidos entonces sobre narcotráfico, la inequidad, la pobreza y la miseria vistos a través del cine, generan un impacto a través de lo simbólico, más si es tratado en la apropiación de materiales de archivo.

Para contar historias que podríamos denominar realidades en pantalla, Fecé-Gómez (2004) menciona cómo la producción audiovisual está ligada a la industria cultural que proviene de grandes corporaciones capitalistas que se encargan de producir y estandarizar una versión de la realidad.

Este tipo de producciones adquieren un componente documental que se emplaza en las ideas de los espectadores, en el impacto de lo preestablecido que se piensa sobre diferentes entornos o lugares, Rincón (2015) afirma que: "El diferencial de la narcotelenovela frente a las telenovelas y series clásicas está en que tienen verdad documental y tono casi neorrealista sobre este fascinante pero cotidiano mundo prohibido del narco, (...) los personajes responden a la estética del grotesco" (p. 95).

Esta idea es desarrollada mencionando cómo los personajes en series propias de Colombia como Escobar el patrón del mal (2012) que tenían como objetivo desmitificar a Pablo Escobar, desde sus primeros capítulos emitidos por televisión nacional, se encarguen de construir una estructura narrativa basada en la violencia, que pone en pantalla los asesinatos de políticos y periodistas como Luis Carlos Galán, candidato presidencial; el ministro de justicia de Colombia, Rodrigo Lara Bonilla, y 
el director del diario El Espectador, Guillermo Cano. Así pues, esta relación con la historia requiere una concentración en su propio uso Ferro (1995) "la lectura cinematográfica de la historia plantea a la historia el problema de su propia lectura del pasado" (p. 25).

En el caso del documental, es entendido como una visión de la realidad propia (Rabiger, 2003). Sin embargo, hoy en día el documental ha generado nuevas interpretaciones que no son vistas en los formatos estudiados sobre el narcotráfico. Reconocer en el cine documental una fuente y un resultado de producción de sentido que supera el régimen audiovisual que lo define, significa considerarlo una práctica discursiva (Dittus, 2013, p.81). El documental representa a través de la lente el mundo que tienen enfrente, Nichols (1997), "vemos imágenes del mundo y lo que éstas ponen ante nosotros son cuestiones sociales y valores culturales, problemas actuales y sus posibles soluciones, situaciones y modos específicos de representarlas" (p.13).

\section{La figura de Pablo Escobar}

En Colombia, y en el mundo, Pablo Escobar Gaviria se convirtió en la figura que representó la imagen del narcotráfico en la década de los ochentas y noventas. Alrededor de dicha figura se generaron diferentes versiones y rumores sobre su historia, estas han sido representadas en las series que hacen parte de este estudio. Escobar nació el 1 de noviembre de 1949 en Rionegro, Antioquia, Colombia. Sus inicios en la delincuencia se remontan a actividades caracterizadas como delincuencia común, robos, contrabando y el cultivo y comercialización de drogas ilícitas como la cocaína. Fue el máximo jefe del cartel de Medellín, organización delincuencial que instauró el terror en Colombia entre los años 1992 y 1996.

En las series estudiadas es posible identificar los siguientes hechos de violencia: La primera foto de Pablo Escobar Gaviria: fotografía que el periodista Guillermo Cano reveló en su diario El Espectador. En la edición del 25 de agosto de 1983, El Espectador reprodujo la publicación de 1976. Escobar es elegido congresista: relata las disputas y hechos de Pablo Escobar con la política en Colombia, en 1982 fue elegido por la cámara de representantes. Asesinato de Rodrigo Lara: el 30 de abril de 1984 fue asesinado el ministro a manos de los hombres de Pablo Escobar. Asalto al palacio de Justicia: 6 de noviembre de 1985 fue tomado el Palacio de Justicia con incidencia de Pablo Escobar para borrar los archivos que lo comprometían en investigaciones asociadas al narcotráfico. Asesinato de Guillermo Cano: el 17 de diciembre de 1986 es asesinado el periodista Guillermo Cano por orden de Pablo Escobar. Asesinato de Luis Carlos Galán: el 18 de agosto de 1989 es asesinado el candidato presidencial Luis Carlos Galán Sarmiento. Bomba de Avianca: en 1989 se comete un atentado contra un avión de Avianca con el interés de asesinar al presidente César Gaviria Trujillo, sucesor de Luis Carlos Galán Sarmiento. Bomba en el DAS: el 6 de diciembre de 1989 es detonada una bomba en el Departamento Administrativo de Seguridad. Asalto a la Catedral: el 22 de julio de 1992 la policía retoma el poder en la cárcel donde permanecía Pablo Escobar. La captura de Pablo Escobar: el 2 de diciembre de 1993 es asesinado Pablo Escobar en la ciudad de Medellín.

\section{Memoria a través del audiovisual y los usos del material de archivo}

La relación entre cine e historia ha sido objeto de múltiples análisis dentro del campo académico. Desde distintas perspectivas, el cine es entendido como un espejo que refleja realidades históricas, una fuente y agente de información sobre el pasado. Es, además, producto cultural de la sociedad y enmarcado en una época específica, así es basado en la historia y hace parte de la historia en sí mismo. Algunos casos que demuestran lo anterior se ven reflejados en el cine alemán y las narrativas del holocausto. Ferro (1995), un problema en cuanto a la propia lectura del pasado.

En sus diferentes géneros, el cine documental desde sus inicios ha generado procesos de cons- 
trucción de memoria, bien sea desde la vista retrospectiva de las imágenes producidas, como en la construcción inmediata que ha abordado temas sociales, ambientales, que retratan la cultura abordando además procesos históricos. Este formato aborda el archivo audiovisual como herramienta narrativa. Desde el punto de vista histórico, el archivo es usado como una herramienta que permite aplicaciones dentro de la comprobación de hechos verídicos. La imagen se ejecuta como mecanismo probatorio de la realidad, como un rastro de la historia que vive dentro de una pieza audiovisual. Este es el caso de El Archivo Nacional de la Memoria de la Ciudad de Buenos Aires, que es el responsable de la preservación y estudio de la documentación referente a las violaciones de los derechos humanos en la Argentina, y que incluye, además, la custodia y análisis de los testimonios que integran el archivo de la Comisión Nacional sobre Desaparición de Personas.

También se encarga de la obtención, análisis, clasificación, duplicación, digitalización y archivo de informaciones, testimonios y documentos sobre el quebrantamiento de los derechos humanos y las libertades fundamentales en que esté comprometida la responsabilidad del Estado Argentino y sobre la respuesta social e institucional ante esas violaciones, este archivo ha sido pionero en América Latina en el uso de documentos como prueba y elemento para la judicialización. Calvo de Castro y Ramos (2019) mencionan: "El cine documental argentino ya había mostrado en el periodo anterior su vinculación con procesos de recuperación de la memoria, [...] las investigaciones cinematográficas son una parte esencial de la esfera social" (p.45). Algo similar pasa con el archivo de prensa de la Universidad de Antioquia, visitado a diario por las víctimas para documentar su condición. Por esta razón señalamos la importancia del registro noticioso en el conflicto armado "El registro noticioso de un hecho violento, ocurrido dentro del conflicto armado, puede ayudar a las víctimas a documentar sus solicitudes para que sean asistidas por la Ley de Víctimas y Restitución de Tierras (Ley 1448 de 2011).

Así como la prensa constituye un elemento probatorio del pasado, de los hechos y situaciones vividas, la imagen de archivo constituye una prueba directa que permite tanto a los espectadores como a los investigadores generar un puente directo de tiempo entre el pasado y el presente que posibilitó no solo la corroboración o prueba de lo sucedido sino dar una visión actual con una base en el pasado. El conocido Programa de la UNESCO Conservación de la Memoria del Mundo, es la base de la que partimos para analizar una determinada situación que tiene que ver con la conservación de los documentos audiovisuales que producen los medios de comunicación de este tipo. Nada hay tan omnipresente en nuestra Sociedad de la Información como los medios de comunicación audiovisuales y, sin embargo, nada hay tan fugitivo como los productos que emiten. Esta situación ya fue expuesta por la UNESCO en 1980, aprobando en su Conferencia General una serie de recomendaciones para la salvaguarda y conservación de las imágenes en movimiento. Ronco-López (2009) afirma:

El pasado como entidad fundamental para la construcción de un presente sustenta las normas e intereses de Naciones Unidas para la conservación de los documentos audiovisuales, más allá de ese carácter anecdótico con el que se ha caracterizado el archivo, las funciones fundamentales del archivo se han establecido a través de una serie de usos que han hecho fundamental la conservación de la memoria (p. 1).

Los materiales de archivo se incorporan a los productos audiovisuales con diversas aplicaciones, influyendo de formas diferentes dependiendo de las particularidades de los géneros narrativos. Propiamente en los contenidos de ficción, este material aporta en muchas ocasiones a la noción orden cronológico, que se imprime en la narrativa dando a los filmes un tono documental, De la Cuadra y López (2021) aclaran, sobre los usos del material en la ficción, que la forma "Caracteriza a estas películas un cierto tono de documental, aun siendo ficción. Se han llamado docudramas, real-ficción, y otras denominaciones que intentan mezclar en el mismo sustantivo el gran aporte de información (supuestamente veraz) que fluye en el film y la narración de ficción (p.12). La incorporación de material de archivo en los formatos de ficción ha generado otros términos como el de re- 
al-fiction, Gómez (2005) en De la Cuadra y López explican "En la real-fiction se construyen nuevas obras gracias a la unión y utilización de todos los géneros disponibles: ficción, reportajes, archivos, efectos especiales, imágenes de síntesis" (p.15). Lo anterior es complementado con el concepto de docu-fiction y faction acuñados por Raventós, Torregrosa y Cuevas (2012) "En los últimos años se percibe también un uso creciente de nuevos términos ... la expresión faction, cada vez más frecuente en Estados Unidos para designar largometrajes, telefilmes o miniseries docudramáticos y también del término docu-fiction" (p.125), así pues, la incorporación del material de archivo a los productos audiovisuales está mediada por su misma naturaleza, Pérez Puente, 1996 en López de Solís (2015) plantea cómo "el documento audiovisual se caracteriza por ser múltiple, multiforme, incompatible, dependiente, opaco y ambiguo" (p.42).

La definición e identificación de elementos formales está directamente relacionada con los impactos generados por el material de archivo en la sociedad, esto hace que sea necesario reflexionar sobre el componente ético, los cuales tienen que ver con el uso y el impacto del archivo en los medios de comunicación, bien sea escritos o audiovisuales, a esto López de Solís (2015) expone que, la incorporación del material de archivo puede ser subjetiva, teniendo en cuenta que no está asociada a la intención cómo y para qué fue creado el material, filmado con una mirada y con una voluntad distinta a la del documentalista. Además, los usos de dichos materiales, pueden comprometer las decisiones tomadas por los implicados en los materiales noticiosos, Cohen-Almagor (2005) menciona como han sido revelados movimientos militares y el posible uso de la fuerza militar en programas informativos y la prensa. (p. 392). Díaz-Campo, Chaparro-Domínguez y Rodríguez-Martínez (2018) complementa:

Las recomendaciones sobre la cobertura informativa de actos terroristas. el primero, sobre los terroristas, aborda cuestiones como autoría, difusión de su identidad, tratamiento de contenidos suministrados por ellos, contextualización, adjetivación, tratamiento de sus familiares o la relación con los cuerpos de seguridad; el apartado relativo a las víctimas trata su identidad y la privacidad de fallecidos, supervivientes, menores y personas vulnerables; el apartado dedicado a la audiencia analiza las fuentes informativas, la advertencia de emisión de imágenes duras, la espectacularización, las imágenes de archivo o el uso de material generado por usuarios; los dos apartados finales se dedican a periodistas y autoridades, y abordan la relación entre ambos (p.1360).

Así pues, las formas narrativas no son lo único a analizar, el archivo audiovisual tiene particularidades asociadas a temas e impactos vinculados a la violencia. Al poner en pantalla terroristas que han asesinado y generado un sinnúmero de desastres; en el caso de esta investigación que ha impactado tanto la sociedad colombiana como la sociedad internacional. Para lo anterior Sánchez Duarte (2009), plantea:

El terrorista insurgente necesita publicidad. Sus acciones se conciben, cada vez más, en relación a normas de marketing y consumo mediático. Los medios de comunicación invaden cualquier ámbito de una sociedad mediatizada a la que también le corresponde un terrorismo mediatizado. Desde los inicios del terrorismo ya se identificaron los réditos que reportaba la propaganda.....Las acciones terroristas no son de puertas para adentro (al menos las de grupos insurgentes). Para que estas organizaciones sobrevivan necesitan figurar en las noticias fabricando eventos convulsos dotados de la espectacularidad, novedad y letalidad suficientes (p.82).

Lo anterior presenta el amplio espectro de significados y usos del material de archivo que impactan los productos en los cuales están incorporados.

\section{Cuestiones metodológicas}

Para el estudio de las adaptaciones sobre la figura de Pablo Escobar en el siglo XXI fueron estudiadas 20 producciones, todas las adaptaciones realizadas durante el periodo de $2000-2018$. Se analizaron 8 contenidos de ficción; 3 seriados de ficción y 5 largometrajes, además de 12 contenidos documentales. En dicho análisis se utilizó la metodología cualitativa y cuantitativa a 
través de herramientas como el análisis fílmico, lo que permitió generar la clasificación inicial, la sistematización e identificación de elementos narrativos, en este caso tomando el material de archivo audiovisual como elemento a estudiar y contrastar en sus usos tanto en ficción -unitaria y seriada-, como en documental - unitario y seriado -. LaTabla 1 muestra la clasificación de las obras analizadas.

Tabla 1. Producciones analizadas

\begin{tabular}{|c|c|c|c|c|c|}
\hline \multicolumn{6}{|c|}{ Muestra } \\
\hline & Título & Año & $\begin{array}{l}\text { Tipo de } \\
\text { contenido }\end{array}$ & $\begin{array}{l}\text { Documental } \\
\text { ficción }\end{array}$ & Director \\
\hline 1 & Blow & 2001 & Largometraje & Ficción & Ted Demme \\
\hline 2 & The True Story of Killing Pablo & 2002 & Serie & Documental & David Keane \\
\hline 3 & $\begin{array}{l}\text { Los archivos privados de Pablo } \\
\text { Escobar }\end{array}$ & 2004 & Largometraje & Documental & Luigui Baquero \\
\hline 4 & Zero Hour. The King of Cocaine & 2004 & Serie & Documental & Renny Bartlett \\
\hline 5 & Pablo Escobar, ángel o demonio & 2007 & Largometraje & Documental & Jorge Granier \\
\hline 6 & Pecados de mi padre & 2009 & Largometraje & Documental & Nicolás Entel \\
\hline 7 & 30 for 30 & 2009 & Serie & Documental & $\begin{array}{l}\text { Jeff Zimbalist and Mike } \\
\text { Zimbalist }\end{array}$ \\
\hline 8 & El Patrón del mal capítulo piloto & 2009 & Serie & Ficción & Carlos Moreno \\
\hline 9 & Pablo's Hippos & 2010 & Largometraje & Documental & $\begin{array}{l}\text { Lawrence Elman, } \\
\text { Antonio Von Hildebrand }\end{array}$ \\
\hline 10 & Los Tiempos de Pablo Escobar & 2012 & Serie & Documental & Alessandro Angulo \\
\hline 11 & Escobar: Paraíso perdido & 2014 & Largometraje & Ficción & Andrea Di Stefano \\
\hline 12 & $\begin{array}{l}\text { Narcos temporada } 1 \text { capitulo } \\
\text { piloto }\end{array}$ & 2015 & Serie & Ficción & José Padilha \\
\hline 13 & $\begin{array}{l}\text { Narcos temporada } 2 \text { capítulo } \\
\text { piloto }\end{array}$ & 2015 & Serie & Ficción & José Padilha \\
\hline 14 & Facing Escobar & 2016 & Serie & Documental & $\begin{array}{l}\text { Adrian Buitenhuis, Derik } \\
\text { Murray }\end{array}$ \\
\hline 15 & Infiltrado & 2016 & Largometraje & Ficción & Brad Furman \\
\hline 16 & Barry Seal: El traficante & 2017 & Largometraje & Ficción & Doug Liman \\
\hline 17 & Loving Pablo & 2017 & Largometraje & Ficción & $\begin{array}{l}\text { Fernando León de } \\
\text { Aranoa }\end{array}$ \\
\hline 18 & Finding Escobar's Millions & 2017 & Serie & Documental & Douglas Laux \\
\hline 19 & $\begin{array}{l}\text { Countdown to Death: Pablo } \\
\text { Escobar }\end{array}$ & 2017 & Largometraje & Documental & $\begin{array}{l}\text { Santiago Díaz, Pablo } \\
\text { Martín Farina }\end{array}$ \\
\hline 20 & Drug Lords & 2018 & Serie & Documental & James Mahoney \\
\hline
\end{tabular}

Fuente: Elaboración propia

El corpus de la investigación es analizado a través del diálogo de varias metodologías, dando un orden en cuanto a la identificación del producto, clasificando los tipos de materiales a estudiar, recopilando datos claves sobre ficha de producción, compuesta por el año, el país, el género, el formato, la duración, entre otros. Ficha que se acoge a lo propuesto por Tarín y Felici (2007) para la metodología en el análisis fílmico, la tarea que se desarrolló fue deconstruir los elementos a estudiar y al mismo tiempo identificarlos y describirlos. 
Gómes-Tarín (2006) propone descomponer el filme en sus elementos constituyentes [y] establecer relaciones entre tales elementos para comprender y explicar los mecanismos que les permiten constituir un todo significante. Carmona (1993) plantea la importancia de tener en cuenta un contexto (tipo de producción, género, nacionalidad, estilemas autorales, etc.) que fuerza ciertas direcciones de lectura, un modo de ver y leer (p. 55).

Lo anterior da paso a la identificación de elementos como el material de archivo. Dicha identificación permite analizar, cualificar y cuantificar el uso de los elementos de archivo vinculados a los elementos de la realidad; se toman en cuenta otros componentes del análisis fílmico para la descripción y la interpretación, Tarín y Felici (2007) plantea la conexión entre descripción e interpretación, donde las conexiones cobran vida. Plantea además un gráfico útil para esclarecer el proceso (Figura 1).

Figura 1. Estructura análisis fílmico

Deconstrucción - Descripción - Interpretación - Enumeración - Ordenación articulación - Reconstrucción

Fuente: (Gómez-Tarín, 2006. p. 8)

Para lograr generar una disección se plantea un análisis de la estructura en tres puntos centrales, compuestos por los componentes objetivables, los componentes no objetivables y la interpretación de los anteriores, tomado del método de análisis fílmico de Gómez-Tarín los siguientes elementos: La Figura 2 presenta los elementos principales para el abordaje del análisis fílmico.

Figura 2. Elementos análisis fílmico

\begin{tabular}{|c|}
\hline Elementos objetivables: \\
Un entorno de producción (análisis contextual) \\
Elementos no objetivables: \\
Enunciación y punto de vista \\
Interpretación (elementos subjetivos) \\
Interpretación global b. Juicio crítico \\
\hline Fuente: (Gómez-Tarín, 2006. p. 8)
\end{tabular}

El eje fundamental del componente objetivable está relacionado con la información correspondiente a los elementos concretos de la producción audiovisual, es decir, los elementos dispuestos en la ficha técnica; el primero corresponde a la nacionalidad de la producción, este elemento nos permitirá contrastar el tipo de contenido generado según el país de origen donde fue realizada la producción. Rabiger (2005) dice que "debemos tener en cuenta que la producción de significado no es independiente de su sistema económico de producción ni de los instrumentos y las técnicas de las que se sirven las individualidades para elaborar materiales que produzcan un significado" (p. 43).

El segundo momento está compuesto por los componentes no objetivables dentro de los cuales incluimos el punto de vista y la enunciación del personaje tanto de Pablo Escobar como de otros personajes hacia él, tanto en documental como en ficción. Además de estos elementos de enunciación incluímos un análisis correspondiente a las tipologías de los documentales estudiados, teniendo en cuenta las categorías estructuradas por Nichols (1997), antes mencionadas en el texto. El material de archivo es otro de los componentes a identificar, que, si bien es un material concreto, está en la línea del tiempo del filme. Es un material que corresponde a diferentes tipologías y orígenes como 
son: archivos familiares, material de prensa, material audiovisual de noticias, noticias reconstruidas y archivos personales. Las anteriores tipologías permiten generar un proceso de identificación catalogado mediante los usos dispuestos en el filme.

El material es clasificado teniendo en cuenta los usos asociados a la catalogación planteada por Lanza (2010) la cual plantea diferentes usos del material: el archivo como ilustración, evocación, instrumento de denuncia. Además, se sistematiza la proveniencia y el tipo de archivo, es decir, archivo familiar, archivo de noticias de prensa, noticias de televisión o radio. Identificando, además, la reconstrucción ficcionada de noticias, lo cual es recurrente en los filmes estudiados. Lo anterior, haciendo una diferencia entre usos y tipos de materiales.

Para el estudio se diseñó un instrumento compuesto por 4 segmentos. En el primer segmento se realiza la identificación del filme, tomando como referencia los elementos no objetivables y el entorno de producción como: género, país, equipo de proyección, la ventana de exhibición y un espacio que permite generar observaciones sobre dichos aspectos. La segunda fase contempla los géneros del filme, tipologías y clasificación documental, según las categorías de Nichols (1997). El segundo segmento del instrumento identifica la cantidad de material de archivo utilizado, con el fin de identificar la duración de este, lo que da paso a las características de estos productos; basados en el autor Lanza (2014) y complementados en los usos de dicho material, como noticias o tipos de noticias: prensa, radio, televisión o noticias ficcionadas. La Tabla 2 muestra el instrumento para la clasificación y analisis de los contenidos.

Tabla 2. Instrumento, ficha de análisis para la identificación del contenido

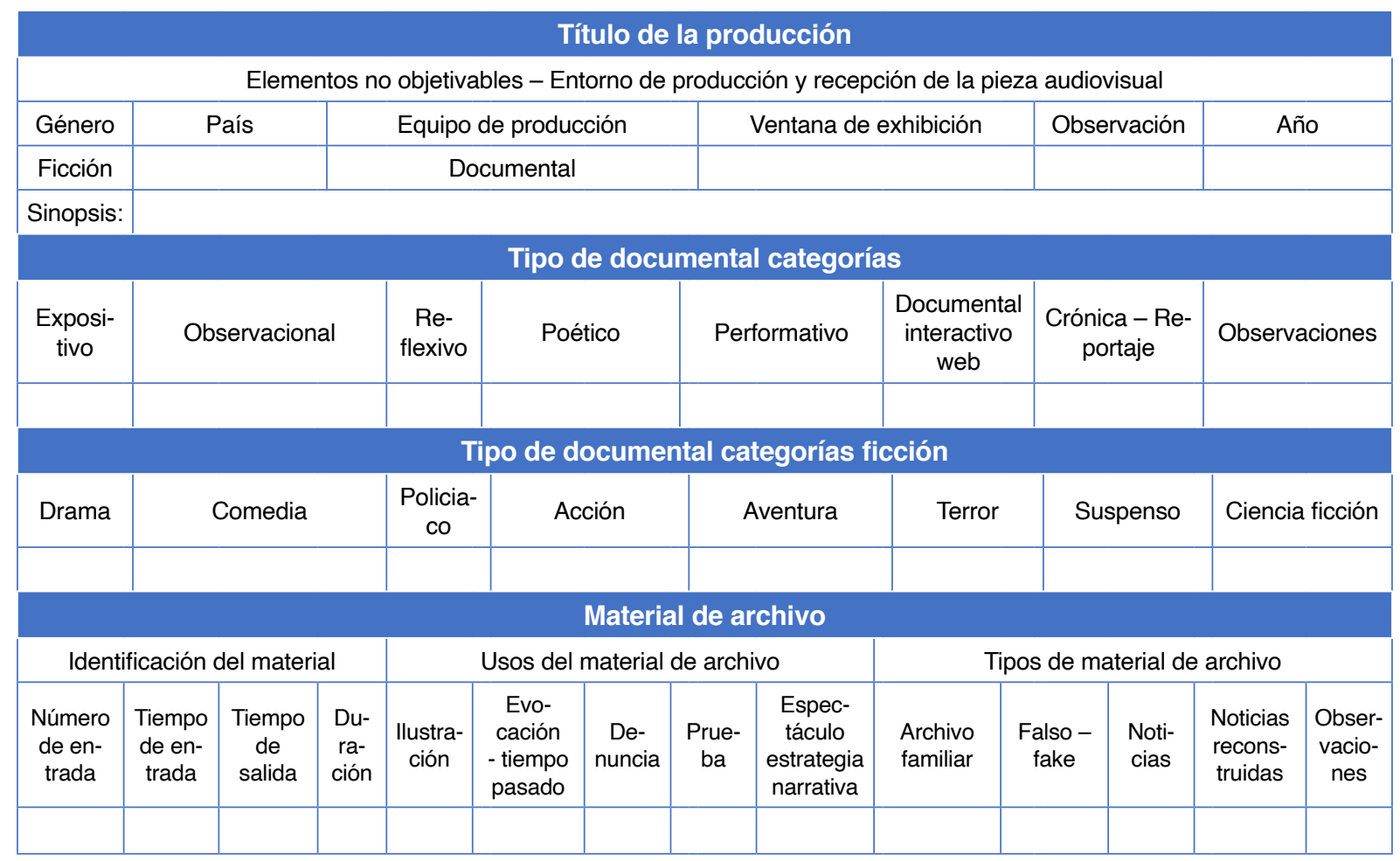

Fuente: Elaboración propia

\section{Resultados}

Los resultados arrojados por el instrumento, en el primer momento de identificación, permiten identificar que, de una muestra compuesta por 20 producciones, estas están clasificadas de la siguiente 
manera: 7 largometrajes documentales, 5 series documentales, 5 largometrajes de ficción, 3 series de ficción. La Tabla 3 presenta la clasificación y el total de los productos analizados.

Tabla 3. Clasificación de la producción

\begin{tabular}{|c|c|}
\hline Tipo de contenido & Producciones \\
\hline Largometraje documental & 7 \\
\hline Serie documental & 5 \\
\hline Largometraje de ficción & 5 \\
\hline Serie de ficción & 3 \\
\hline Total & 20 \\
\hline
\end{tabular}

Fuente: Elaboración propia

\subsection{Producción por países}

La producción por países de estos contenidos se comporta de la siguiente manera: 3 de los contenidos analizados son de producción colombiana, otro es producción canadiense, una producción Colombo-Argentina, uno corresponde a producción española, 10 de los productos analizados son realizados en los Estados Unidos, otro corresponde a Francia y otro a Venezuela. El 50\% de la producción sobre Escobar es producida con la mirada estadounidense sobre el fenómeno del narcotráfico. La Tabla 4 presenta la clasificación de la producción por países.

Tabla 4. Producción por países

\begin{tabular}{|c|c|}
\hline País o países de la producción & Producción \\
\hline CANADÁ & Zero hour \\
\hline \multirow{3}{*}{ COLOMBIA } & Escobar el patrón del mal \\
\hline & Los archivos privados de Pablo Escobar \\
\hline & Los tiempos de Pablo Escobar \\
\hline COLOMBIA - ARGENTINA & Pecados de mi padre \\
\hline ESPAÑA & Loving Pablo \\
\hline \multirow{11}{*}{ ESTADOS UNIDOS DE AMÉRICA } & Barry Seal \\
\hline & Blow \\
\hline & Countdown to Death Pablo Escobar \\
\hline & Drug Lords \\
\hline & El Infiltrado o Operación Escobar \\
\hline & Facing Pablo Escobar \\
\hline & Los dos Escobar \\
\hline & Los millones de Pablo \\
\hline & Narcos T1, C1 \\
\hline & The true story of killing Pablo \\
\hline & Narcos T2 E1 \\
\hline FRANCIA & Escobar: El paraíso perdido \\
\hline INGLATERRA & Pablo's Hippos \\
\hline VENEZUELA & Pablo Escobar. ¿Ángel o demonio? \\
\hline
\end{tabular}

Fuente: elaboración propia 


\subsection{Material de archivo}

Con respecto al material de archivo, encontramos que, de 372 entradas de material de archivo, 92 entradas corresponden a archivos familiares, 21 entradas corresponden a archivos recreados, el mayor número de material de archivo corresponde a archivo de noticias, 226 entradas y 26 de las entradas "parecen" ser noticias, pero generando un análisis en profundidad, son secuencias de ficción que se recrean con el formato de noticias. La Tabla 5 muestra los tipos de materiales de archivo y la presencia en escena.

Tabla 5. Tipos de material de archivo

\begin{tabular}{|l|c|}
\hline \multicolumn{1}{|c|}{ Tipos de material de archivo } & Entradas de material \\
\hline Archivo familiar & 99 \\
\hline Archivo recreado & 21 \\
\hline Noticias & 226 \\
\hline Noticias reconstruidas & 26 \\
\hline Total, entradas & 372 \\
\hline
\end{tabular}

Fuente: elaboración propia

La Tabla 6 presenta las clasificación de las noticias presentes en escena.

Tabla 6. Tipo de noticias presentes en la escena

\begin{tabular}{|l|c|}
\hline \multicolumn{1}{|c|}{ Tipo } & \# de entradas \\
\hline Radio & 1 \\
\hline Televisión & 207 \\
\hline Prensa & 18 \\
\hline Total & 226 \\
\hline
\end{tabular}

Fuente: elaboración propia

\subsection{Usos de material de archivo en las producciones}

Teniendo en cuenta las categorías planteadas, podemos analizar que la cantidad de usos del material de archivo no es utilizado como un componente de prueba, denuncia, ni en su mayoría como evocación. Más bien es usado como una ilustración de los lugares, personajes y situaciones. 342 entradas corresponden a la categoría de ilustración, 213 a la categoría de evocación, 34 entradas a la categoría de denuncia, 56 entradas en la categoría de prueba y 47 en la categoría de estrategia narrativa que comprende la necesidad de incluir material para acompañar un testimonio de entrevista. Los documentales en su mayoría son los que contienen este tipo de material, producciones como Los archivos privados de Pablo Escobar (2004), Pablo's Hippos (2010) y Drug Lords (2017) contienen la mayor cantidad de archivo audiovisual, ya que corresponden al formato de entrevista acompañados de material audiovisual ilustrativo. Es importante mencionar que las entradas analizadas pueden corresponder a una o mas categorías de archivo; en la tabla 7 podemos identificar el desglose planteado anteriormente. La Tabla 7 muestra la clasificación de los usos y el tipo de material de archivo analizado. 
Tabla 7. Usos del material de archivo y tipos de material de archivo

\begin{tabular}{|c|c|c|c|c|c|c|c|c|}
\hline \multirow[t]{3}{*}{ Producción } & \multicolumn{8}{|c|}{ Usos del material de archivo y tipos de material de archivo } \\
\hline & \multicolumn{8}{|c|}{ Entradas discriminadas por categoría } \\
\hline & $\begin{array}{l}\text { llustra- } \\
\text { ción }\end{array}$ & $\begin{array}{c}\text { Evocación- } \\
\text { tiempo } \\
\text { pasado }\end{array}$ & $\begin{array}{l}\text { Denun- } \\
\text { cia }\end{array}$ & Prueba & $\begin{array}{l}\text { Espectá- } \\
\text { culo es- } \\
\text { trategia } \\
\text { narrativa }\end{array}$ & $\begin{array}{l}\text { Archivo } \\
\text { familiar }\end{array}$ & $\begin{array}{l}\text { Falso - } \\
\text { fake }\end{array}$ & $\begin{array}{c}\text { \# de } \\
\text { entradas } \\
\text { por obra }\end{array}$ \\
\hline Zero hour & 43 & 19 & 15 & 3 & 3 & 15 & & 43 \\
\hline Barry Seal & 3 & 1 & & & 3 & & & 3 \\
\hline Countdown to Death Pablo Escobar & 46 & 57 & 1 & & & 14 & & 57 \\
\hline Drug Lords & 22 & 24 & 5 & 5 & 8 & 2 & 2 & 24 \\
\hline El patrón del mal & & 27 & & & 1 & & & 27 \\
\hline El Infiltrado & 3 & 1 & & 1 & 2 & & & 3 \\
\hline Escobar paraíso perdido & 3 & 2 & & 1 & 2 & & 1 & 3 \\
\hline Escobar sin censura & 8 & 8 & 1 & 9 & 1 & 15 & 1 & 8 \\
\hline Los millones de pablo & 6 & 1 & & & & 2 & & 6 \\
\hline Los Archivos Privados de Pablo Escobar & 21 & 2 & 1 & 12 & 3 & 17 & & 21 \\
\hline Los dos Escobar & 10 & 4 & & 4 & 3 & 4 & & 10 \\
\hline Los tiempos de Pablo Escobar & 61 & 37 & & 1 & & & & 61 \\
\hline Loving Pablo & 1 & & & & & & 10 & 10 \\
\hline Narcos T1 CAP 1 & 2 & & & & & & & 2 \\
\hline Narcos T2 & 3 & & & & 2 & & & 3 \\
\hline Pablo Escobar. ¿Ángel o demonio? & 12 & 7 & & & 2 & & & 12 \\
\hline Pablo's Hippos & 51 & 23 & 11 & 15 & 17 & 1 & 6 & 51 \\
\hline Pecados de mi Padre & 6 & & & 4 & & 14 & & 14 \\
\hline Película Blow & & & & & & & 1 & 1 \\
\hline The True Story of Killing Pablo & 40 & & & 1 & & 15 & & 40 \\
\hline Total de categorias encontradas & 341 & 213 & 34 & 56 & 47 & 99 & 21 & \\
\hline & & & & & & & otal de er & radas 372 \\
\hline Las entradas ar & das $p$ & den corres & nder a u & a o mas & ategorias & archivo & & \\
\hline
\end{tabular}

Fuente: Elaboración propia

Los usos del material de archivo presentan una tendencia de 341 ilustraciones, 213 evocación del tiempo pasado, 34 entradas a la categoría de denuncia, 56 entradas en la categoría de prueba y 47 en la categoría de estrategia narrativa que comprende la necesidad de incluir material para acompañar un testimonio de entrevista. En su mayoría los contenidos realizados corresponden al formato documental, de serie y de largometraje. Sigue predominando el formato de largometraje en los dos géneros, en cuanto a contenidos seriados en total son 9 que corresponden a 3 de ficciones y 6 documentales.

Las 20 obras analizadas están clasificadas de la siguiente manera: 12 contenidos documentales, divididos en 5 series y 7 largometrajes; 8 obras corresponden al género de ficción, de ellas 3 series y 5 largometrajes; 11 de las obras son producidas en EE. UU.; 6 obras colombianas; 1 coproducción con Inglaterra y dos de las obras son producidas en Europa. Uno de los productos seleccionados en la muestra no pudo ser analizado, ya que fue imposible acceder a él, no se encuentra en plataformas y el director no respondió a la solicitud de la investigación para analizar dicha producción. El producto al cual nos estamos refiriendo es Ciudadano Escobar (2004) del director Colombiana Sergio Cabrera.

En cuanto a los contenidos documentales, obedecen principalmente a la categoría de expositiva según las clasificaciones de Nichols (1997), lo cual se expresa en su mayoría a través de materiales ilustrativos y voz en off en su contenido. 


\subsection{Clasificación de los contenidos documentales}

En la tabla anterior que incluye los países de los cuales proviene la producción, podemos identificar cómo sólo uno de los documentales incluye la narrativa observacional dentro de sus estrategias narrativas, además encontramos cómo en su mayoría los documentales realizados en los Estados Unidos presentan la categoría de documental reflexivo, asociado a la crónica o el reportaje. Solo uno de los documentales incluye el componente performativo dentro de su narrativa.

\subsection{Tipologías del documental}

Dentro de las categorías documentales, en su mayoría, los contenidos obedecen a la tipología expositiva, la cual está basada principalmente en un proceso de presentación de hechos, para transmitir al espectador el punto de vista del realizador, esta tipología de documental es una de las tipologías más antiguas basada en la entrevista y el material de apoyo. Teniendo en cuenta lo anterior podemos identificar además cómo es predominante la estética de la crónica y el reportaje, ya que el eje estructural de los contenidos documentales analizados son las entrevistas y los testimonios recolectados. No se encontraron contenidos relacionados con las categorías observacional o poético, y solo se observaron contenidos pertenecientes a la categoría reflexiva en la serie Los dos Escobar. Tampoco se encuentran exploraciones desde el documental interactivo. La Tabla 8 presenta la clasificación de los contenidos documentales.

Tabla 8. Clasificación de contenidos documentales

\begin{tabular}{|c|c|c|c|c|c|c|c|c|c|}
\hline País & $\begin{array}{l}\text { Tipo de } \\
\text { contenido }\end{array}$ & Producción & $\begin{array}{l}\text { Expo- } \\
\text { sitivo }\end{array}$ & $\begin{array}{l}\text { Obser- } \\
\text { vacio- } \\
\text { nal }\end{array}$ & $\begin{array}{l}\text { Re- } \\
\text { flexi- } \\
\text { vo }\end{array}$ & Poético & $\begin{array}{l}\text { Perfor- } \\
\text { mativo }\end{array}$ & $\begin{array}{c}\text { Documen- } \\
\text { tal inte- } \\
\text { ractivo } \\
\text { web }\end{array}$ & $\begin{array}{l}\text { Crónica - } \\
\text { Reportaje }\end{array}$ \\
\hline Estados Unidos & Documental & $\begin{array}{l}\text { Countdown to } \\
\text { Death Pablo } \\
\text { Escobar }\end{array}$ & $\mathrm{X}$ & & & & & & \\
\hline Estados Unidos & Documental & Drug Lords & & & & & & & $x$ \\
\hline Estados Unidos & Documental & $\begin{array}{l}\text { Escobar sin } \\
\text { censura }\end{array}$ & $x$ & & & & & & \\
\hline Estados Unidos & Documental & $\begin{array}{l}\text { Los millones de } \\
\text { pablo }\end{array}$ & & & & & $x$ & & $x$ \\
\hline Estados Unidos & Documental & $\begin{array}{l}\text { Los dos Es- } \\
\text { cobar }\end{array}$ & & & $x$ & & & & \\
\hline Estados Unidos & Documental & $\begin{array}{l}\text { The True Story } \\
\text { of Killing Pablo }\end{array}$ & $x$ & & $x$ & & & & \\
\hline Colombia & Documental & $\begin{array}{l}\text { Los archivos } \\
\text { privados de } \\
\text { pablo escobar }\end{array}$ & $x$ & & & & & & $x$ \\
\hline Colombia & Documental & $\begin{array}{l}\text { Los tiempos de } \\
\text { Pablo Escobar }\end{array}$ & $x$ & & & & & & \\
\hline Venezuela & Documental & $\begin{array}{l}\text { Pablo Escobar. } \\
\text { ¿Ángel o de- } \\
\text { monio? }\end{array}$ & $x$ & & & & & & \\
\hline Inglaterra & Documental & Pablo's Hippos & $x$ & & & & & & \\
\hline $\begin{array}{l}\text { Colombia } \\
\text { Argentina }\end{array}$ & Documental & $\begin{array}{l}\text { Pecados de mi } \\
\text { Padre }\end{array}$ & $x$ & & & & & & $x$ \\
\hline Canadá & Documental & Zero Hour & $x$ & $x$ & & & & & \\
\hline
\end{tabular}

Fuente: Elaboración propia 


\section{Discusión}

El material de archivo identificado en las producciones corresponde a un proceso de ilustración mediante el cual se pretende contextualizar al espectador en una historia de ficción con referencias reales. Las producciones dan una suerte de contextualización en la cual son usados mapas, fechas, fotografías y materiales de archivo que se comparten, como la declaración de Ronald Reagan para la lucha antidrogas, la primera fotografía de Pablo Escobar de su entrada a prisión, así como las míticas imágenes de la hacienda Nápoles en las cuales se ve a Pablo Escobar utilizando motocicletas junto a otros narcotraficantes. Se reconstruye así el imaginario estadounidense del narcotráfico.

El archivo familiar se emplea para humanizar el personaje, mediante la puesta en pantalla de fotografías de su niñez, de su juventud y su adolescencia. Fotografías y videos que des-enmarcan al personaje de su papel de delincuente, por el contrario, presentan una suerte de crecimiento del narcotraficante y sus logros. Parte de los contenidos están conectados con historias contadas a través de la literatura como es el caso del Patrón del Mal, adaptación de la novela La parábola de Pablo (2001) o The Infiltrator, Mazur (2016) que lleva el mismo título de la película El infiltrado (2016).

Otros casos como el documental de la serie 30 for 30 (2009) los dos Escobar, vinculan materiales de archivo del fenómeno futbolístico vivido en Colombia en los años 90, época donde ocurrió el asesinato del futbolista Andrés Escobar, hecho que no tiene ninguna relación con el Narcotraficante Pablo Escobar, se establece una relación del impacto del narcotráfico en los negocios del fútbol en aquella época. Sin embargo, al ser un documental los materiales de archivo son usados para contar una época inmersa en el fenómeno narco. Esta suerte de uso para el espectáculo conecta palabras claves como Escobar, narcotráfico y realidad. En los diferentes formatos de ficción y documental, se presenta una gran diferencia de uso del material de archivo, siento en ficción un elemento netamente narrativo que vincula la historia con los hechos ocurridos, mientras que en el documental se pone a disposición de toda la historia para acompañar la narración. El caso de documentales como The true Story of Killing Pablo retoma el archivo como una prueba de lo sucedido con todo tipo de categorías, como archivos familiares, noticias entre otras y usos del archivo como fotografías, documentos, vídeos y audios, que narran los lugares; así como elementos fundamentales que retoman los hechos históricos, incluyendo testimonios como el del entonces candidato presidencial Luis Carlos Galán Sarmiento.

Se incluyen, además, hechos históricos de violencia como el asesinato de policías, el atentado al Departamento Administrativo de Seguridad (DAS) y el atentando al avión de Avianca perpetuado por el narcotraficante Pablo Escobar Garviria, que tenía como objetivo el asesinato del entoces presidente César Gaviria Trujillo. Se encuentra material de prensa e imágenes en video de los entrenamientos a policías por parte de los Estados Unidos, el Bloque de búsqueda, archivos fusionados con elementos que no corresponden a la línea temporal como la violencia paramilitar. Historia también basada en el libro Killing Pablo Bowden (2001).

Estos contenidos permiten una identificación del origen de las producciones, una visión exclusiva del punto de vista de Estados Unidos. en la lucha contra el narcotráfico, dejando de lado a las víctimas y poniendo en pantalla a la policía de los Estados Unidos. como salvadores del conflicto, todo lo anterior soportado en el archivo. Estos contenidos documentales desde su parte formal son un $50 \%$ de entrevista y un 50\% de material de archivo que acompaña los discursos. En muchos de los productos teniendo en cuenta lo anterior se desconoce el papel de los colombianos como Guillermo Cano, Luis Carlos Galán y Rodrigo Lara Bonilla entre otros que lucharon incansablemente contra el narcotráfico en Colombia. 


\section{Conclusiones}

Retomando el objetivo central del artículo de examinar las adaptaciones sobre la figura de Pablo Escobar en el siglo XXI, se estudiaron 20 producciones de diferentes géneros, de las cuales en su mayoría son productos realizados en los Estados Unidos. demostrando una narración sobre el tema del narcotráfico, basada en los puntos de vista de Estados Unidos. 11 de las obras analizadas son producidas por los Estados Unidos. Solo 3 de los productos son de origen colombiano, 1 producto en coproducción con Argentina, un producto realizado en España, otro en Canadá y otro en Inglaterra. Pocos contenidos sobre dicha temática son desarrollados en el país afectado por la problemática del narcotráfico.

Los materiales utilizados en estas producciones son usados en el caso de ficción generando una vinculación con la realidad, historias construidas a partir de las ideas de sus realizadores, que incorporan el material de archivo generando nuevas realidades expuestas en pantallas internacionales. El material de archivo es usado principalmente con el fin de ilustrar lugares, personajes y situaciones.

En ficción, específicamente en la película Loving Pablo (2017) se encontraron 11 entradas de material de archivo, que corresponden a una ilustración y 10 como reconstrucciones de archivos. En la serie Narcos Temporada 1 (2015) se encontraron 4 entradas de archivo usadas como un componente ilustrativo, la serie en Narcos Temporada 2 (2015), se encontraron 5 archivos, 3 de ellos usados principalmente como ilustración y como estrategia narrativa. En la película Blow (2001) se encontró solo una entrada de archivo que corresponde a una reconstrucción ficticia del archivo. En series como $E l$ Patrón del Mal (2012) se encuentran 27 entradas del material de archivo con el objetivo de evocar la vida del narcotraficante. Vemos cómo los usos de material de archivo en ficción son vinculados principalmente como una estrategia narrativa instaura a través de los contenidos audiovisuales con estereotipos ficcionales, teniendo en cuenta que gran parte de las verdades puestas en pantalla provienen de materiales reconstruidos y usados como estrategia narrativa para construir un personaje como Pablo Escobar vinculado a historias de ficción que resalta en su inicio que es un contenido ficcional.

En el formato documental, los archivos son usados de forma diferente, constituyen diferentes categorías como la de archivo familiar, con un total 114 archivos, este tipo de información proviene de fotos de la infancia y la adolescencia, con una función de humanizar al personaje de Escobar, la otra cantidad de archivo es usado de forma ilustrativa en su mayoría con un tipo de documental según las categorías de Nichols (1997) expositivo, categoría que no aporta a la reflexión sobre el narcotráfico en Colombia, como sí lo haría un tipo de documental reflexivo.

Los usos de material de archivo en estas producciones asociadas al narcotráfico, tanto en ficción como en documental, perpetúan la construcción de estereotipos, ya que, en ficción, vinculan archivos reconstruidos o archivos falsos, se evidencian un total de 21 entradas en esta categoría. En documental son usados archivos familiares que humanizan el personaje de Escobar, así como material de archivo vinculado a imágenes de noticias, 162 entradas se evidencian en esta categoría, la cual aporta a la construcción de productos expositivos que narran a través de la imagen un personaje como Escobar.

\section{Bibliografía}

Becerra, A. (2018). Investigación documental sobre la narcocultura como objeto de estudio en México. Documentary research on narcoculture as an object of study in Mexico, 6, 1-36. https:// doi.org/10.22234/recu.20180601.e349

Becerra, A. y Hernández, D. (2019). Fascinación por el poder: consumo y apropiación de la narcocultura por jóvenes en contextos de narcotráfico. Intersticios sociales. 17, 259-285. http:// www.intersticiossociales.com/index.php/is/article/view/235/pdf 
Bowden, M. (2001). Killing Pablo: The Hunt for the World's Greatest Outlaw. Atlantic Monthly Press.

Calvo-de-Castro, P. y Marcos, M. (2019). La ausencia y la memoria en el cine documental argentino". La configuración del discurso narrativo a través de cuatro películas de principios del siglo XXI". Cine documental. 17, 32 -53. https://revista.cinedocumental.com.ar/la-ausencia-yla-memoria-en-el-cine-documental-argentino-la-configuracion-del-discurso-narrativo-a-traves-decuatro-peliculas-de-principios-del-siglo-xxi/

Carmona, R. (1993). Cómo se comenta un texto filmico. Madrid. Cátedra.

Cohen-Almagor, R. (2005). Media Coverage of Acts of Terrorism: Troubling Episodes and Suggested Guidelines. Canadian Journal of Communication, 30(3), 383 - 409.

Díaz-Campo, J., Chaparro-Domínguez, M. Á., \& Rodríguez-Martínez, R. (2018). Los atentados terroristas de Barcelona y Cambrils en la prensa online. Tratamiento informativo en El periódico, El país y The guardian. Profesional de la Información, 27(6), 1358-1367. https://doi.org/10.3145/ epi.2018.nov.18

De la Cuadra, E. y López, I. (2021). Imágenes de archivo en cine de ficción: cine basado en una historia real. Communication. Trípodos. Tendències en documentació dels mitjans de comunicació, $31,11-36$.

Dittus. R (2013). El realismo estético del cine documental en la tesis de Pier Paolo Pasolini. Aisthesis, 53, 141-157. http://dx.doi.org/10.4067/S0718-71812013000100008

Fecé-Gómez, J. (2004). Representación y cultura audiovisual en la sociedad contemporánea. Editorial UOC.

Ferro, M. (1995). Historia contemporánea y cine. Editorial Ariel.

Gómez-Tarín, F. (2006). El análisis del texto filmico. Universitat Jaume I.

Lanza, P. (2010). Usos del archivo en el cine documental latinoamericano contemporáneo: los documentos sobrevivientes. Cine documental. 1. http://revista.cinedocumental.com.ar/1/ articulos_03.html

López de Solís, I. (2015). El uso de la documentación audiovisual en programas informativos no diarios de TVE: "Informe Semanal, En portada y Crónicas". Universidad Complutense de Madrid.

Tarín, J. y Felici, M. (2007) Metodologías de análisis del filme. Edipo.

Morales, E. y Carrillo, G. (2017). Antropología y literatura sobre drogas y narcotráfico: México y Colombia. Cuadernos Americanos, 161, 195-219. http://www.cialc.unam.mx/cuadamer/textos/ ca161-195.pdf

Nichols, B. (1997). La representación de la realidad. Paidós.

Rabiger, M. (2003). El documental y la poesía (Miguel Ángel Fernández, trad.). Revista litoral, 236, 283-292. https://revistas.pedagogica.edu.co/index.php/revistafba/article/view/6281

Rabiger, M. (2005). Dirección de documentales. Instituto Oficial de Radio y Televisión, Colección de manuales profesionales.

Raventós, C., Torregrosa, M. y Cuevas, E. (2012). El docudrama contemporáneo: rasgos configuradores. Trípodos, (29), $117-132$. 
Rivas Frías, B. (2020). Cine de autor peruano en tiempos de globalización: entre la transgresión y la marginación. Revista de comunicación, 19. https://revistadecomunicacion.com/article/ view/1948/1593

Rodríguez-Blanco, S. y Mastrogiovanni, F. (2018). Narrativas hegemónicas de la violencia. El crimen organizado y el narcotráfico entre el periodismo y las ficciones televisivas. Anàlisi. Quaderns de Comunicación i Cultura, 58, 89-104. https://ddd.uab.cat/pub/analisi/analisi a2018n58/analisi a2018n58p89.pdf

Rincón, Ó. (2009). Narco.estética y narco. cultura en Narco.lombia. Nueva Sociedad, (222), 147163. https://nuso.org/media/articles/downloads/3627_1.pdf

Rincón, Ó. (2015) Amamos a Pablo, odiamos a los políticos. Las repercusiones de Escobar, el patrón del mal. Nueva Sociedad, 255, 94-105. .https://biblat.unam.mx/hevila/ Nuevasociedad/2015/no255/8.pdf

Ronco-López, M. (2009) Los documentos audiovisuales y su conservación. Dokumentazio zerbitzuak Euskal Herriko komunikabideetan. Los servicios de documentación en los medios de comunicación del País Vasco, 73-100. Euskal Herriko Unibertsitatea. Universidad del País Vasco. http://eprints.rclis.org/15786/1/4.pdf

Sánchez-Duarte, J. (2009). Narrativas y portavoces del terrorismo mediatizado. Revista latina de comunicación social, 12 (64). 481 - 490. https://doi.org/10.4185/RLCS-64-2009-839-481-490

Santos, D. (2016). Lo Narco Como Modelo Cultural. Una Apropiación Transcontinental. Mitologías Hoy. (14), 9-23. Http://Dx.Doi.Org/10.5565/Rev/Mitologias.401

Williams, R. (1997). Marxismo y Literatura. Península. http://www.afoiceeomartelo.com.br/ posfsa/Autores/Williams, $\% 20$ Raymond/Marxismo\%20y\%20literatura.pdf

\section{Filmografía}

Angulo, A. (Director). (2012). Los Tiempos de Pablo Escobar. [Serie]. Colombia: Laberinto Cine y Televisión.

Andrea, D. (Director). (2012). Escobar: Paraíso perdido. [Película]. Francia, España: Roxbury Pictures Pathé. Alta films.

Baquero, L. (Director). (2004). Los archivos privados de Pablo Escobar. [Película]. Colombia: Divina producciones.

Bartlett, R. (Director). (2004). Zero Hour. The King of Cocaine. [Serie]. Estados Unidos: Cineflix Productions.

Buitenhuis, A y Murray D. (2016) Facing Escobar. [Serie]. Estados Unidos: Network Entertainment.

Cabrera, S. (Director). (2004). Ciudadano Escobar. [Película] Colombia: De La Mancha

Productions, Plural Entertainment.

De Aranoa, F. (Director). (2017). Loving Pablo. [Película]. España: Escobar Films, B2Y EOOD.

Demme, T. (Director). (2001). Blow [Película]. Estados Unidos: New Line Cinema.

Díaz, S. y Martín, P. (Director). (2017). Countdown to Death: Pablo Escobar. [Película]. Estados Unidos: Netflix. 
Entel, N. (Director). (2009) Pecados de mi padre. [Película]. Colombia, Argentina: Arko Vision. CIA Argentina. SRL.

Elman, L. y Hildebrand, A. (Director). (2010). Pablo sHippos. [Película]. Inglaterra: 11:11 Films.

Furman, B. (Director). (2016). Infiltrado. [Película]. Estados Unidos: Broad Green Pictures, Good Films.

Granier, J. (Director). (2007) Pablo Escobar, ángel o demonio. [Película]. Venezuela: Sierralta Entertainment, Angostura Film.

Keane, D. (Director). (2002). The True Story of Killing Pablo. [Serie]. Estados Unidos: Wild Eyes Productions.

Padilha, J. (Director). (2015). Narcos. [Serie]. Estados Unidos: Netflix.

Liman, D. (Director). (2017). Barry Seal: El traficante. [Película]. Estados Unidos: Universal Pictures.

Laux, D. (Director). (2017). Finding Escobar's Millions. [Serie]. Estados Unidos: Blackfin, Pixeldust Studio.

Mahoney, J. (Director). (2017). Drug Lords. [Serie]. Estados Unidos. ITN Productions. Distribuidora: Netflix.

Moreno, C. (Director). (2009). El Patrón del mal. [Serie]. Colombia: Canal Caracol.

Zimbalist, J. y Zimbalist, M. (Director). (2009). 30 for 30. [Serie]. Estados Unidos: ESPN 